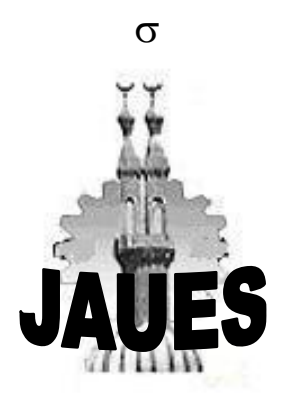

Journal Of Al Azhar University Engineering Sector

Vol. 12, No. 42, January, 2017, 213-222

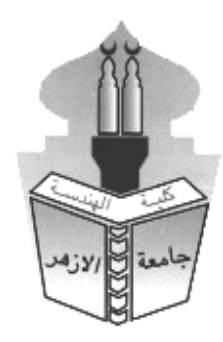

\title{
WATER CONING CORRELATIONS IN VERTICAL WELLS
}

\author{
Ramadan Emara \\ (Home) Al Azhar University, Faculty of Eng., Mining and Petroleum Eng. Department \\ (Secondment)The British University in Egypt, Faculty of Eng., Petroleum and Natural Gas \\ Technology Department
}

\begin{abstract}
One of the major problems that reduces significantly the crude oil production is water coning. When the well is produced, water moves up from the bottom water toward the wellbore in a cone shape. At certain conditions, water breaks through into the well and concurrent oil and water production starts.

Many methods have been presented to overcome this problem, whatever before or after the taking place of water coning. The critical rate is the widely method used to overcome this problem before its occurring.

The aim of this paper is to introduce a method to predict the critical rate, breakthrough time, and WOR (water oil ratio) after breakthrough in vertical wells. A 3-D numerical simulator model was used to perform a comprehensive sensitivity analysis of water coning process. From this analysis, an empirical coning correlation was developed based on the basic flow equations and regression analysis. The format of the correlation is similar to Addington's gas-coning and Yang's water coning correlations.

The correlations presented in this paper provide a hand calculation fashion of coning prediction for vertical wells. The correlations were tested and found to be reliable and accurate in predicting the critical rate, breakthrough time and WOR, within the correlation parameter range.
\end{abstract}

\section{Keywords: Water coning; Critical rate; Water production.}

\section{INTRODUCTION}

Water coning is the expression describing the upward movement of water into the perforations of producing wells that are produced from oil layers underlain by bottom water. Several problems arise due to the excessive production of water from oil wells such as decrease in oil flow rate, decrease efficiency in the depletion mechanism and hence loss of field total overall recovery. Produced water is often corrosive and thereby increase in water disposal cost.

During production from an oil well underlain by bottom water, there are two forces that control the movements of oil-water contact, the pressure gradients and gravity forces. When the pressure gradients are dominant, the oil-water contact can be raised near the well and the coning of water will break into the well to produce water along with the oil. The gravity forces that arise from fluid density differences counterbalance the flowing pressure gradients and tend to keep the water out of the oil zone. Numerous authors have dealt with the coning problem in terms of critical rate, water 
breakthrough time, and water-oil ratio (WOR) after water breakthrough. Many approaches have been developed for predicting these behaviors.

Several correlations were developed to predict the critical rate. In general, these correlations can be divided into two groups. The first group determines the critical rate analytically based on the equilibrium conditions of the pressure gradients and gravity forces. Muskat and Wyckoff developed an approximate solution of the critical flow rate in isotropic formations. They solved Laplace's equation for single phase, steady-state, incompressible flow. Meyer and Garder ${ }^{2}$ simplified the analytical solution of Muskat and Wyckoff work for radial- flow, whereas Chaney et al. $^{3}$ and Chierici et al. ${ }^{4}$ used potentiometric models to obtain the critical flow rate. Chaperon ${ }^{5}$ investigated the water coning in vertical wells in anisotropic formations in a closed system and presented a solution for the critical rate and reported that the critical rate increases slightly when the vertical permeability decreases, but the elevation of the critical cone does not change appreciably. Wheatly ${ }^{6}$ took into account the influence of cone shape on the oil potential, which others had not done before. Tabatabaei et al. ${ }^{7}$, presented an analytical model to calculate the optimum completion interval and the critical flow rate for a steady state flow from a vertical well that is partially completed in an anisotropic reservoir with a low pressure gradient.

The second group is empirical correlations. Schols ${ }^{8}$ presented an expression from experiments conducted in his lab, while Hoyland et al. ${ }^{9}$ developed their correlation from computer simulation runs. Addington ${ }^{10}$ presented generalized expressions for the critical coning rate and the gas-liquid ratio (GLR) after gas breakthrough employing a three-dimensional simulation study of the Prudhoe Bay field. The concept of Addington for calculating the critical rate was different from others. Addington was solving a closed outer boundary problem that never reaches steady-state conditions, while others were dealing with open outer boundary problems at steady-state conditions. Moreover, Addington's critical rate is decreasing with time, while others had a constant critical rate.

Methods are also available to predict the water breakthrough time. Sobocinski and Cornelius ${ }^{11}$ presented dimensionless correlating groups in forms of dimensionless plot based on their experimental and computer simulation runs for a homogeneous, incompressible system with no gas cap, producing at a constant rate to calculate the cone breakthrough time and critical rate. Bournazel and Jeanson ${ }^{12}$ conducted laboratory experiments and developed a correlation for the water breakthrough time in vertical wells similar to the correlation of Sobocinski and Cornelius. Also they developed a method assuming that water is separated from oil, the oil-water interface rises and stays at some point of perforation interval. By determining the length of the perforation interval in the water, WOR can be calculated. Byrne and Morse ${ }^{13}$, Mungan ${ }^{14}$, Blades and Strightll ${ }^{15}$ searched the effects of different reservoir and well variables on WOR performance using numerical simulation. However, they had not reached to a general predictive model. Kuo and DesBrisay ${ }^{16}$ presented an expression for predicting water cut performance based on a sensitivity analysis of water coning performance for different reservoir parameters using numerical simulation. Yang and Wattenbarger ${ }^{17}$ presented correlations to predict the critical rate, breakthrough time and WOR after breakthrough for water coning in vertical and horizontal wells. This work presents water-coning correlations for predicting the critical rate, water breakthrough time and WOR after breakthrough for vertical wells.

\section{Method}

Yang and Wattenbarger ${ }^{17}$ noticed that the relationship between the WOR plus a constant (c) and the average oil column height below perforations after water breakthrough $\left(\mathrm{h}_{\mathrm{bp}}\right)$ on a semi-log scale is a straight line as shown in Fig. 1. They described this diagram mathematically as follows:

$\mathrm{WOR}=0$

$$
\begin{aligned}
& \mathrm{h}_{\mathrm{bp}}>\mathrm{h}_{\mathrm{wb}} \\
& \mathrm{h}_{\mathrm{bp}}<=\mathrm{h}_{\mathrm{wb}}
\end{aligned}
$$

Where, $\mathrm{h}_{\mathrm{wb}}$ is the average oil column height below perforation at breakthrough, $\mathrm{S}$ is the slope of the straight line and $\mathrm{C}$ is a constant. 
In the presented work, a method for determining $h_{w b}, S$ and $C$ was developed from a stepwise procedure. First, a number of simulation runs was made to analyze the performance of coning at different reservoir and fluid properties. Then, for each run, (WOR $+C)$ was graphed against $h_{b p}$ on a semi-log scale, from which $S$ and $h_{w b}$ were determined using regression analysis. Once the $h_{w b}$ and $S$ data was obtained for all the simulation runs, regression analysis was then used to define the relationship between $\mathrm{S}, \mathrm{h}_{\mathrm{Wb}}$ and different reservoir and fluid properties, respectively.

\section{Correlations Development}

In this paper Eclipse, a black-oil, three-dimensional, commercial simulator was used to simulate the water coning in a vertical well. The formation is considered to be homogeneous and anisotropic with capillary forces. The vertical well is modeled with a 3-D, r-z model as shown in Fig.2.

To develop correlations to calculate the water breakthrough height and slope of the straight line after breakthrough, the parameters sensitivity analysis was made to supply the required data. The relative permeability data is illustrated in Table 1.

A base case was installed to start the parameters sensitivity analysis. Afterwards each parameter was varied from the lower value to the upper value of its range in each simulation run. The parameters used in the sensitivity analysis are oil flow rate, horizontal and vertical permeabilities, drainage radius, net pay thickness, perforation and above perforation thicknesses, oil and water viscosities, porosity and water-oil gravity difference.

In Table 2, the simulation data and outcomes are illustrated. The base case parameters values are shown in the top line. For the rest of the cases reported, the parameters are varied independently over the range presented in the table while preserving the values of the remainder of the parameters in the base case. A blank space displays that the base case value is carried forward. The average oil column height below perforation at breakthrough $\mathrm{h}_{\mathrm{wb}}$ and slope of the straight line $\mathrm{S}$ are recorded in the last two column. For a particular variable under investigation, a semi-log plot of (WOR+C) vs. $\mathrm{h}_{\mathrm{bp}}$ was made. From the plot, $\mathrm{h}_{\mathrm{wb}}, \mathrm{S}$ and $\mathrm{C}$ are obtained. It was found that the constant, $\mathrm{C}$, is 0.25. Then, the WOR changes can be described by the following equation.

$$
\begin{array}{ll}
\text { WOR }=0 & h_{b p}>_{h w b} \\
\log (W O R+0.25)=S\left(h_{b p}-h_{w b}\right)+\log (0.25) & h_{b p}<=h_{w b}
\end{array}
$$

After investigating the effect of the various reservoir and fluid properties on $h_{w p}$ and $S$, the following equations were defined as follows.

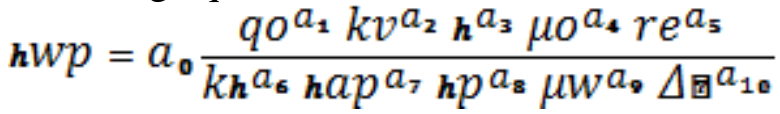

Where

$$
\begin{aligned}
& \mathrm{a}_{0}=0.307116 \\
& \mathrm{a}_{3}=1.181052 \\
& \mathrm{a}_{6}=0.046041 \\
& \mathrm{a}_{9}=0.036 \\
& S=b_{0} \frac{k h^{b_{1}} h^{b_{2}} \mu W^{b_{3}} \Delta \mathbb{0}^{b_{3}} q o^{b_{5}}}{k v^{b_{6}} h a p^{b_{7}} \boldsymbol{h} p^{b_{8}} \mu o^{b_{9}} r e^{b_{10}}-1}
\end{aligned}
$$

Where
$\mathrm{b}_{0}=1.106253$
$\mathrm{b}_{3}=0.016241$
$\mathrm{b}_{6}=0.018312$
$\mathrm{b}_{9}=0.0306$

$$
\begin{aligned}
& \mathrm{b}_{1}=0.050788 \\
& \mathrm{~b}_{4}=0.000746 \\
& \mathrm{~b}_{7}=0.000639 \\
& \mathrm{~b}_{10}=0.07
\end{aligned}
$$

\section{Correlations Validation}

$$
\begin{array}{ll}
\mathrm{a}_{2} & =0.05255 \\
\mathrm{a}_{5} & =0.0765 \\
\mathrm{a}_{8} & =0.183205
\end{array}
$$

$\mathrm{b}_{2}=0.036605$

$b_{5}=0.0016$

$b_{8}=0.004854$ 
In order to validate the accuracy of the derived correlations, a statistical analysis has been used to evaluate their performance. The statistical indicators are presented in the appendix. The obtained outcomes include an average relative error (ARE) of 0.013, 0.006 an average absolute relative error (AARE) of $0.74,0.39$ and regression coefficient $\left(R^{2}\right)$ of $0.99,0.9$ for $h_{w p}$ and $S$ correlations, respectively.

\section{Calculation example}

An oil well with the following data, calculate the critical rate, time at breakthrough and WOR performance after breakthrough.

$\begin{array}{lllll}\mathrm{h}_{\mathrm{wp}}, \mathrm{ft}= & 161.8 & \mu_{\mathrm{o}}, \mathrm{cp} & = & 1.11 \\ \mathrm{~h}_{\mathrm{p}}, \mathrm{ft}= & 20 & \mu_{\mathrm{w}}, \mathrm{cp} & = & 0.3 \\ \mathrm{k}_{\mathrm{h}}, \mathrm{md}= & 200 & \rho_{\mathrm{o}}, \mathrm{lb} / \mathrm{ft} 3 & = & 50 \\ \mathrm{k}_{\mathrm{v}}, \mathrm{md}= & 20 & \rho_{\mathrm{w}}, \mathrm{lb} / \mathrm{ft} 3 & = & 62.4 \\ \mathrm{~h}, \mathrm{ft}= & 200 & \Phi & = & 0.2 \\ \mathrm{~h}_{\mathrm{ap}}, \mathrm{ft}= & 10 & \beta_{\mathrm{o}}, \mathrm{bbl} / \mathrm{STB} & = & 1.364 \\ \mathrm{r}_{\mathrm{e}}, \mathrm{ft}= & 2000 & \mathrm{r}_{\mathrm{w}}, \mathrm{ft} & = & 0.5\end{array}$

Obtained results

Equation 3 for $h_{w b}$ can be used as a critical rate correlation. At the height $h_{w b}$ water breaks into the well. Then the oil flow rate in this correlation is the critical coning rate. The following equation is used to calculate the breakthrough time.

$t_{b t}=\frac{\left(N_{p}\right)_{b t}}{q_{o}}$

Where $\left(\mathrm{N}_{\mathrm{p}}\right)_{\mathrm{bt}}$ is the cumulative oil production at breakthrough. From Fig. 3, the average oil column height below perforations $h_{b p}$ is linearly related to the cumulative oil production $\mathrm{Np}$. Then, the cumulative oil production at breakthrough can be calculated from the breakthrough height $\mathrm{h}_{\mathrm{wb}}$ :

$$
\left(N_{p}\right)_{b t}=A \phi\left(1-S_{w c}-S_{o r}-S_{g c}\right)\left(h-h_{w p}-h_{a p}-h_{p}\right)
$$

Table (3) compares the results obtained from the present research with those obtained from some other correlations and simulation. The present correlations show a good match of the critical rate and breakthrough time with the simulation results.

After calculation of S from Eq. 4, use Eq. 2 to calculate WOR for a vertical well. The results were compared with the simulation results. The comparison is shown in Fig. 4. The figures show that the present correlation shows a good match with the simulation results.

\section{CONCLUSIONS}

As presented in this study, the following items were achieved.

- Numerical method was used to study the water coning phenomenon in vertical wells.

- A sensitivity analysis was conducted to estimate the effects of the various reservoir rock and fluid properties on the average oil column height below perforations and slope.

- The developed empirical water coning correlations were derived based on threedimensional simulation results to predict the critical rate, breakthrough time and WOR after breakthrough for vertical wells. 
- The correlations were developed based on the regression analysis using the data from numerical simulations.

- The developed correlations show a good match of the critical rate, breakthrough time and WOR after breakthrough with the simulation results.

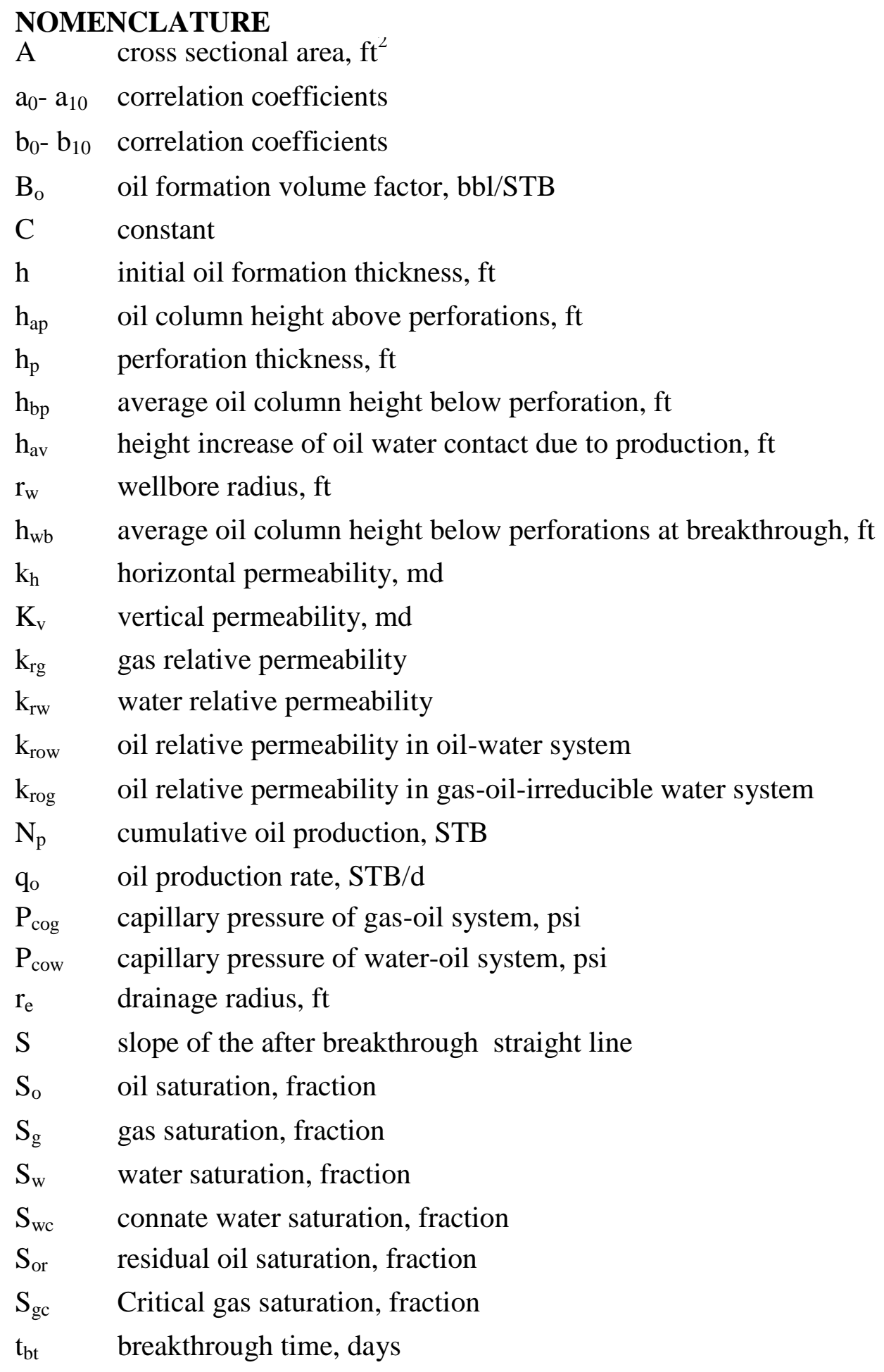




$\begin{array}{ll}\text { WOR } & \text { water-oil ratio } \\ \mu \mathrm{o} & \text { oil viscosity, } \mathrm{cp} \\ \mu \mathrm{w} & \text { water viscosity, } \mathrm{cp} \\ \rho_{\mathrm{o}} & \text { oil density, } \mathrm{lb} / \mathrm{ft}^{3} \\ \rho_{\mathrm{w}} & \text { water density, } \mathrm{lb} / \mathrm{ft}^{3} \\ \phi & \text { porosity, fraction } \\ \Delta \Upsilon & \text { water-oil gravity difference, } \mathrm{psi} / \mathrm{ft}\end{array}$

\section{REFERENCES}

1. Muskat, M. and Wyckoff, R.D.: "An Approximate Theory of Water Coning in Oil Production," Trans. AlME (1935), 114, 144-161.

2. Meyer, H.I., and Garder, A.O.: "Mechanics of Two Immiscible Fluids in Porous Media," Journal of Applied Physics, November 1954, Vol. 25, No. 11, p. 1400.

3. Chaney, P.E., Noble, M.D., Henson, W.L., and Rice, T.D.: "How to Perforate Your Well to Prevent Water and Gas Coning," Oil \&: Gas Journal, May 7, 1956, p. 108.

4. Chierici, G.L., Ciucci, G.M., and Pizzi, G.: "A Systematic Study of Gas and Water Coning by Potentionmetric Models," JPT, August 1964, pp.923-29.

5. Chaperon, I., "Theoretical Study of Coning Toward Horizontal and Vertical wells in Anisotropic formations: Subcritical and Critical Rates," paper SPE 15377 presented at the 1986 SPE Annual Technical Conference and Exhibition, New Orleans, Oct. 5-8.

6. Wheatly, M.I., "An Approximate Theory of Oil Water Coning," SPE Paper 14210, SPE 60th Annual Fall Meeting, Las Vegas, NV, September 22-25, 1985.

7. Tabatabaei, M., Ghlambor, A., Guo, B.: “An Analytical Solution for Water Coning in Vertical Wells" Paper SPE 113106, 2012.

8. Schols, R.S.: "An Empirical Formula for the. Critical Oil Production Rate," Erdoel Erdgas, Z., January 1972, Vol. 88, No.1, pp. 6-11.

9. Hoyland, L.A., Papatzacos, P., Skjaeveland, S.M.: "Critical Rate for Water Coning: Correlation and Analytical Solution," SPE Reservoir Engineering, November 1989.

10. Addington, D.V.: "An Approach to Gas-Coning Correlations for a Large Grid Cell Reservoir Simulator," JPT (November 1981) 2267-74.

11. Sobocinski, D.P., and Cornelius, A.I.: "A Correlation for Predicting Water Coning time," JPT, May 1965, pp.594-600.

12. Bournazel, C. and Jeanson, B.: "Fast Water Coning Evaluation," Paper APE 3628 presented at the SPE 46th Annual Fall Meeting, New Orleans, October 3-6, 1971.

13. Byrne, W.B. and Morse, R.A., "The Effects of Various Reservoir and Well Parameters on Water Coning Performance," paper SPE 4287 presented at the SPE 3rd Numerical Simulation of Reservoir Simulation of Reservoir Performance Symposium, Houston, January 10-12, 1973.

14. Mungan, N.: "A Theoretical and Experimental Coning Study," Soc. Pet. Eng. J. (June 1975) 221-236.

15. Blades, D.N. and Stright, D.H., Ir., "Predicting High Volume Lift Performance in Wells Coning Water," J. Can. Pet. Tech. (October-December 1975) 62-70.

16. Kuo, M.C.T., and DesBrisay, C.L.: "A Simplified Method for Water Coning Predictions," Paper SPE 12067, SPE 58th Annual Fall Meeting, San Francisco, October 5-8, 1983.

17. Yang, W. and Wattenbarger, R. A.: "Water Coning Calculations for Vertical and Horizontal Wells," Paper SPE 22931, SPE Annual Technical Conference and Exhibition, Dallas October 6-9, 1991.

\section{Statistical Error Analysis}


The following three statistical parameters were used in this study to evaluate the accuracy of the correlations.

1- Average percent relative error (ARE)

$$
E_{r}=\frac{1}{n_{d}} \sum_{1}^{n_{d}} E_{i}
$$

Where

$$
E_{i}=\left(\frac{x_{\text {measured }}-x_{\text {estimated }}}{x_{\text {measured }}}\right)_{i} * 100\left(i=1,2, \ldots n_{d}\right)
$$

2- Average absolute percent relative error (AARE)

$$
E_{a}=\frac{1}{n_{d}} \sum_{1}^{n_{d}} E_{i}
$$

$$
r^{2}=1-\sum_{1}^{n_{d}} \frac{\left(x_{\text {measured }}-x_{\text {estimated }}\right)^{2}}{\sum_{1}^{n_{d}}\left(x_{\text {measured }}-x_{\text {avarage }}\right)^{2}}
$$

3- Coefficient of correlation

The lower the value of $E_{\mathrm{r}}$ the more equally distributed are the errors between positive and negative values. The lower value of $\mathrm{E}_{\mathrm{a}}$ the better in the correlation.

The correlation coefficient describes the range of connection between two variables namely experimental and estimated values obtained from the correlation.

The value of $r^{2}$ varies from -1 to +1 . As the value of correlation coefficient approaches +1 , it means there is a strong positive relationship between these two variables.

Table 1. Relative permeability data

\begin{tabular}{|c|c|c|c|c|c|c|c|c|c|c|}
\hline Sw & Krw & Pcow & & Sg & Krg & Pcog & So & Krow & Krog \\
\hline 0.22 & 0 & 1 & & 0 & 0 & 0 & 0 & 0 & 0 \\
\hline 0.3 & 0.051 & 0.5 & & 0.04 & 0 & 0 & 0.2 & 0 & 0 \\
\hline 0.4 & 0.12 & 0.3 & & 0.1 & 0.022 & 0 & & 0.35 & 0 & 0.02 \\
\hline 0.5 & 0.218 & 0.16 & & 0.2 & 0.1 & 0 & & 0.4 & 0.0048 & 0.038 \\
\hline 0.6 & 0.352 & 0.1 & & 0.3 & 0.195 & 0 & & 0.45 & 0.029 & 0.058 \\
\hline 0.7 & 0.5 & 0.05 & & 0.4 & 0.289 & 0 & 0.5 & 0.0649 & 0.102 \\
\hline 0.8 & 0.65 & 0.03 & & 0.5 & 0.42 & 0 & 0.55 & 0.11298 & 0.163 \\
\hline 0.9 & 0.83 & 0.01 & & 0.6 & 0.58 & 0 & & 0.6 & 0.197 & 0.234 \\
\hline 1 & 1 & 0 & & 0.7 & 0.8125 & 0 & & 0.65 & 0.287 & 0.33 \\
\hline & & & & 0.78 & 1 & 0 & & 0.7 & 0.4 & 0.454 \\
\hline & & & & & & & & 0.75 & 0.637 & 0.67 \\
\hline & & & & & & & & 0.78 & 1 & 1 \\
\hline
\end{tabular}


WATER CONING CORRELATIONS IN VERTICAL WELLS

Table 2. Simulation input data and results

\begin{tabular}{|c|c|c|c|c|c|c|c|c|c|c|c|c|c|}
\hline Parameters & qo & $\phi$ & $\mathrm{Kh}$ & $\mathrm{Kv}$ & $\mathrm{h}$ & hap & hp & $\mu \mathrm{o}$ & $\mu \mathrm{w}$ & $\Delta \gamma$ & re & $\mathrm{S}$ & hwp \\
\hline Base Case & 3000 & 0.2 & 200 & 20 & 200 & 10 & 20 & 1.11 & 0.3 & 0.086 & 2000 & -0.0403 & 161.8 \\
\hline 1 & 2000 & & & & & & & & & & & -0.0328 & 160.40 \\
\hline 2 & 2500 & & & & & & & & & & & -0.0398 & 160.90 \\
\hline 3 & 3000 & & & & & & & & & & & -0.0403 & 161.80 \\
\hline 4 & 4000 & & & & & & & & & & & -0.0405 & 163.20 \\
\hline 5 & 5000 & & & & & & & & & & & -0.0406 & 165.60 \\
\hline 6 & & 0.15 & & & & & & & & & & -0.0411 & 161.69 \\
\hline 7 & & 0.2 & & & & & & & & & & -0.0403 & 161.80 \\
\hline 8 & & 0.25 & & & & & & & & & & -0.0405 & 161.79 \\
\hline 9 & & 0.35 & & & & & & & & & & -0.0373 & 162.06 \\
\hline 10 & & 0.4 & & & & & & & & & & -0.0318 & 162.49 \\
\hline 11 & & & 50 & & & & & & & & & -0.1121 & 168.76 \\
\hline 12 & & & 150 & & & & & & & & & -0.0425 & 165.02 \\
\hline 13 & & & 200 & & & & & & & & & -0.0403 & 161.80 \\
\hline 14 & & & 300 & & & & & & & & & -0.0261 & 156.59 \\
\hline 15 & & & 400 & & & & & & & & & -0.0162 & 151.91 \\
\hline 16 & & & & 10 & & & & & & & & -0.0243 & 155.82 \\
\hline 17 & & & & 15 & & & & & & & & -0.0358 & 159.19 \\
\hline 18 & & & & 20 & & & & & & & & -0.0403 & 161.80 \\
\hline 19 & & & & 30 & & & & & & & & -0.0498 & 164.62 \\
\hline 20 & & & & 40 & & & & & & & & -0.0498 & 167.78 \\
\hline 21 & & & & & 110 & & & & & & & \begin{tabular}{l|l}
-0.04 \\
\end{tabular} & 79.70 \\
\hline 22 & & & & & 200 & & & & & & & -0.0403 & 161.80 \\
\hline 23 & & & & & 290 & & & & & & & -0.0267 & 253.30 \\
\hline 24 & & & & & 380 & & & & & & & -0.00176 & 343.00 \\
\hline 25 & & & & & & 10 & & & & & & -0.0403 & 161.80 \\
\hline 26 & & & & & & 20 & & & & & & -0.0398 & 152.71 \\
\hline 27 & & & & & & 30 & & & & & & -0.0406 & 143.53 \\
\hline 28 & & & & & & 40 & & & & & & -0.0401 & 134.86 \\
\hline 29 & & & & & & 50 & & & & & & -0.0419 & 125.87 \\
\hline 30 & & & & & & & 10 & & & & & \begin{tabular}{|l|}
-0.0283 \\
\end{tabular} & 179.48 \\
\hline 31 & & & & & & & 20 & & & & & -0.0403 & 161.80 \\
\hline 32 & & & & & & & 30 & & & & & -0.0411 & 152.15 \\
\hline 33 & & & & & & & 40 & & & & & -0.0404 & 142.78 \\
\hline 34 & & & & & & & 50 & & & & & -0.0421 & 133.00 \\
\hline
\end{tabular}


Table 2. Continued

\begin{tabular}{|l|l|l|l|l|l|l|l|l|l|l|l|l|l|}
\hline 35 & & & & & & & 1.11 & & & & -0.0403 & 161.80 \\
\hline 36 & & & & & & & & 1.61 & & & & -0.0505 & 164.56 \\
\hline 37 & & & & & & & & 2.11 & & & & -0.0491 & 166.63 \\
\hline 38 & & & & & & & & 3.11 & & & & -0.0689 & 168.00 \\
\hline 39 & & & & & & & & 4.11 & & & & -0.0833 & 168.47 \\
\hline 40 & & & & & & & & & 0.2 & & & -0.0481 & 163.75 \\
\hline 41 & & & & & & & & & 0.3 & & & -0.0403 & 161.80 \\
\hline 42 & & & & & & & & & 0.4 & & & -0.0356 & 160.19 \\
\hline 43 & & & & & & & & & 0.5 & & & -0.0330 & 158.49 \\
\hline 44 & & & & & & & & & 0.7 & & & -0.0264 & 156.34 \\
\hline 45 & & & & & & & & & & 0.017 & & -0.0406 & 164.13 \\
\hline 46 & & & & & & & & & & 0.052 & & -0.0405 & 162.80 \\
\hline 47 & & & & & & & & & & 0.086 & & -0.0403 & 161.80 \\
\hline 48 & & & & & & & & & & 0.121 & & -0.0395 & 161.00 \\
\hline 49 & & & & & & & & & & 0.156 & & -0.0385 & 160.30 \\
\hline 50 & & & & & & & & & & 1000 & -0.0107 & 151.22 \\
\hline 51 & & & & & & & & & & & 1500 & -0.0331 & 156.02 \\
\hline 52 & & & & & & & & & & & 2000 & -0.0403 & 161.80 \\
\hline 53 & & & & & & & & & & & 3000 & -0.0708 & 166.01 \\
\hline 54 & & & & & & & & & & & 4000 & -0.1081 & 167.61 \\
\hline
\end{tabular}

Table 3. Comparison with correlations

\begin{tabular}{|c|c|c|}
\hline Correlation & qc, STB/D & Breakthrough time, day \\
\hline Meyer and Garder & 192.4 & \\
\hline Schols & 298 & \\
\hline Chaperon & 140 & \\
\hline Hoyland et al. & 548 & \\
\hline Sobocinski and Cornelius & & 1596 \\
\hline Bournazel and Jeanson & & 697 \\
\hline Yang and Wattenbarger & 1556 & 674 \\
\hline This Study & 3231 & 343 \\
\hline Simulation & 3000 & 350 \\
\hline
\end{tabular}




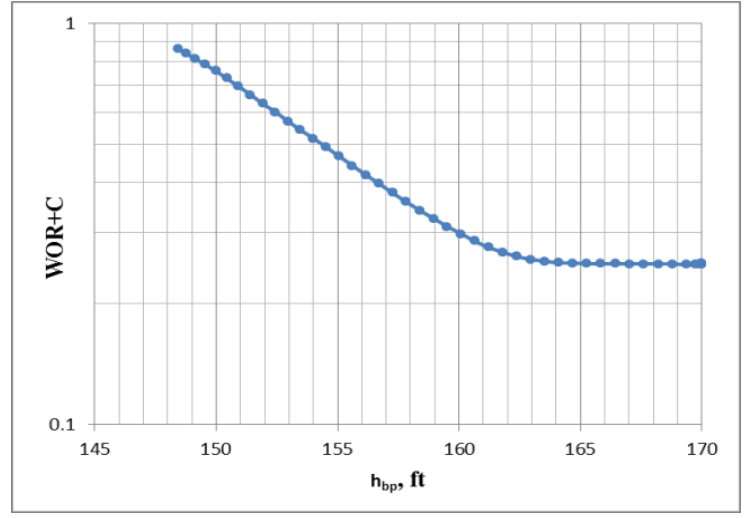

Fig. 1. WOR+C vs. oil column height below perforations from a simulation run

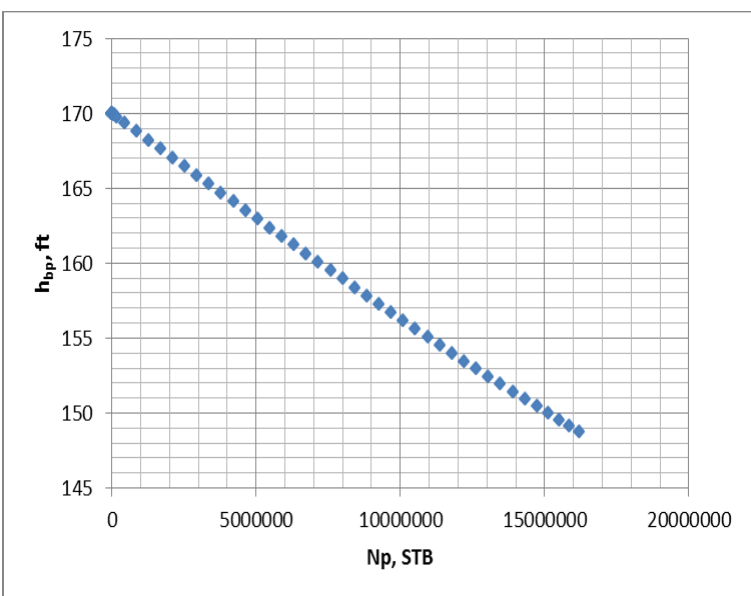

Fig. 3. The relationship between the average oil column height below perforations and the cumulative oil production

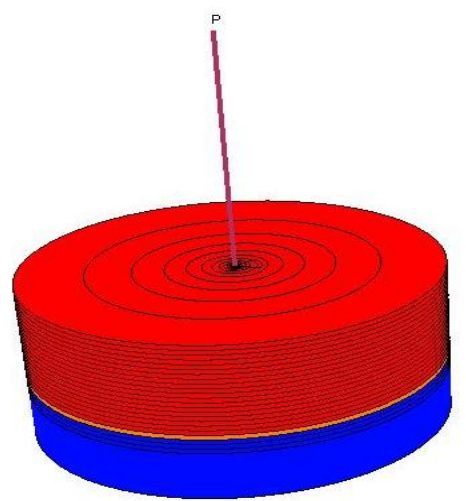

Fig. 2. Simulation grid for a vertical well

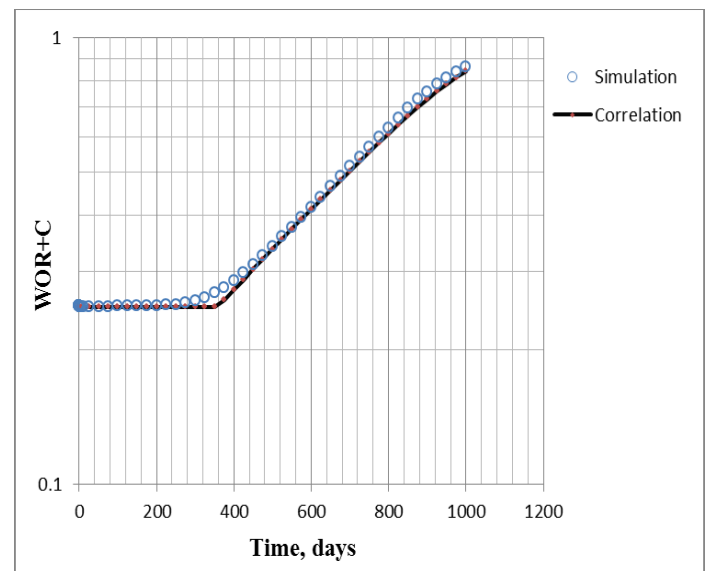

Fig. 4 - WOR+C comparison between simulation and the present correlation 